\title{
Engaging in analytical chemistry in review classes: contests based on TV shows as fun evaluable checkpoints
}

\author{
Rebeca Miranda-Castro ${ }^{1}$ (D) - Noemí de-los-Santos-Álvarez ${ }^{1}$ (D) \\ Published online: 26 February 2020 \\ (C) Springer-Verlag GmbH Germany, part of Springer Nature 2020
}

\section{Introduction}

One of the tools accompanying the change from an instructorcentered to learner-centered education, as a central pillar of the European Higher Education Area, was the embodiment of review sessions in small groups scattered throughout the course in each subject. Homework assignments consisting of problem/ question sets that are solved in the class are the recommended activities by University authorities. In some cases, as our University, these sessions are compulsory and also evaluable. We have noticed that these activities do not motivate students to study hard. On the contrary, students limit their work to solve the few and specific questions (restricted to the allocated time in class), obviating a comprehensive study. This poor study compromises the flourishing of stimulating questions to discuss in these review sessions and most students remain in a passive role unless they are called to explain one of the problems/questions. This attitude leads to students missing the opportunities these review sessions offer to reach an advanced level of knowledge or just to solve the doubts.

In an attempt to engage students in a daily study of Analytical Chemistry, keeping their attention in review sessions that help them to extract the key features of the intricate set of analytical techniques, we show here a pilot gaming project. Gaming promotes active learning [1] and healthy competiveness enliving classroom sessions [2]. On-line instant polling platforms, with and without the need of smartphones, allow anonymity providing a non-threatening environment for students who cannot longer skip participation. They are adapted

Published in the topical collection featuring Female Role Models in Analytical Chemistry.

Noemí de-los-Santos-Álvarez

santosnoemi@uniovi.es

1 Dpto. Química Física y Analítica, Universidad de Oviedo, Julián Clavería 8, 33006 Oviedo, Spain to the generation $Z$ (born between 1995 and 2012) who are digital natives and seem to be more visual and tactile than listening learners and are highly dependent on immediate feedback and reward [3]. Besides, they provide real-time answering simplifying result collection and record keeping [4, 5]. Gamification is more intensively used in primary and secondary schools but it is increasingly common at the university level [1, 2, 6-8] combined with on-line gaming apps [9-11], though slower than expected [12]. Inspired by previous examples using TV quiz show games, such as Who wants to be a chemical millionaire? [1,13], we implemented a tuned version of it in two analytical subjects. Before attendance to the revision gaming classes, students were previously trained during theory sessions in handling different response platforms and in the type of questions they can expect. The biphasic games consisted of a selection phase scored individually to then play the collaborative step scored as a group. After the session, students were asked to take a survey about their experiences. Finally, the learning results were compared with traditional courses.

\section{Implementation of the quiz contests in the course: methodology}

It is important to keep in mind that the activity is mainly an evaluation tool but we wanted to be more ambitious and provide them with feedback that allows them to re-orientate their study according to their results. We are not pursuing gaining extra knowledge but to consolidate the acquired one. Therefore, the aim of implementing quiz contests as an evaluation instrument in review sessions is twofold. On the one hand, promoting a hard comprehensive study during the class period should be mirrored in the learning outcomes. On the other hand, providing an entertainment and friendlier environment for active participation stimulates the formulation of questions and starts fruitful discussions between peers so they can somehow benefit from group study, after checking their 
knowledge with colleagues. Gaming can be a useful and fun tool to help unravel the intricate series of techniques that appear to be the Analytical Chemistry for many students, and to emphasize the more relevant and confusing points.

The gaming sessions were embedded into two subjects: the introductory second-year (2Y) Analytical Chemistry I and third-year (3Y) Analytical Chemistry II, which deal with analytical features, the analytical process, titration and gravimetry, UV-vis and fluorescence molecular spectroscopy, flame atomic spectroscopy, and electroanalytical techniques. In Fig. 1, we show the schedule and methodology of a typical edition of the contest. In each subject, there are four review sessions and we scheduled the quiz contest to the last one to deal with most of the topics. During the first days of the course, we presented the new format of the review sessions to the students. We consider appropriate to train students in the use of the different smartphone applications and advised them to register in order to keep track of the questions answered. With this purpose, we set up two strategies (orange panel in the figure): (i) a forum in the course intranet where the instructors were adding questions and students selected the answer and wrote shortly the reasons behind the decision and (ii) scattered short questions during the theory classes that must be answered using the apps so we were sure all students attending classes regularly are familiar with them before the quiz session.

The day of the review session (blue panel), the precise rules of the contest were presented and the score system remembered. The game consisted in two phases implemented in 50-min sessions with a maximum number of 10 students per session. The initial phase consisted of five simple questions that can be quickly answered by using Kahoo.it, a mobile phone-based polling app, with the purpose of selecting the group leaders. The app ranked participants on both correctness and response speed but we graded each student only according to the former because of differences in connection speed between smartphone brands. This accounted for $50 \%$ of the session mark to discourage
Fig. 1 Flow chart for the implementation of the contest activity in a review session: presentation, training, contestbased review session, and evaluation of the project

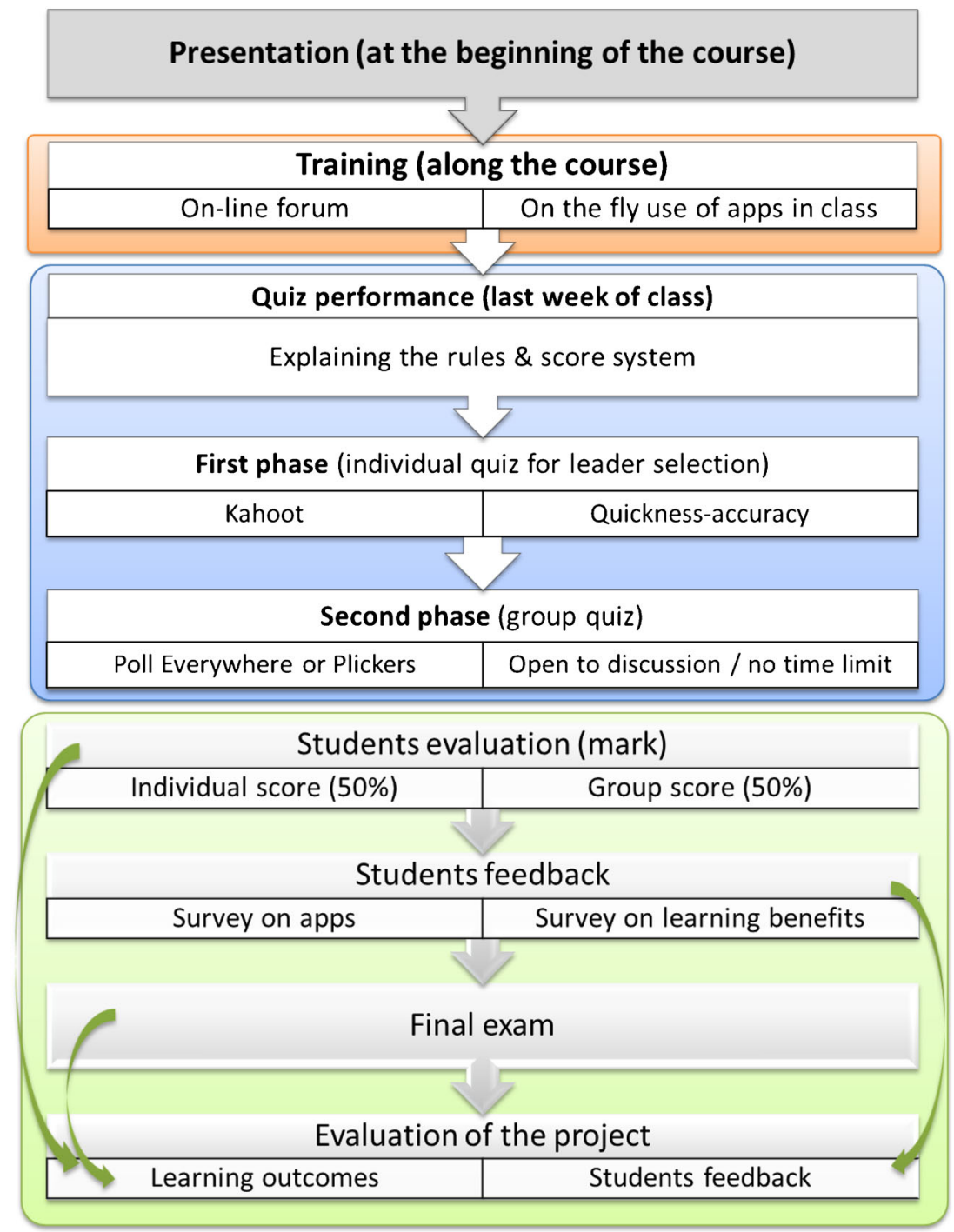


students to respond incorrectly to avoid taking the responsibility of being the leaders in the second phase.

The second part was the TV-based game. We prepared 15 questions of increasing difficulty. Second-year students used Plickers, a mobile free polling system that requires the use of individually assigned cards displaying a squared form with a letter at each side. Rotating the card to show the letter that corresponds to the correct answer in the upper part is the only action students need to do. The instructor scans simultaneously all cards and the results are immediately displayed on the screen. Thirdyear students used Poll Everywhere, a mobile-based polling app that secures anonymity with a back channel for instructors to collect this hidden information if desired. In both cases, the game consisted of answering fifteen questions. All 3Y students were urged to answer the questions but only the leader decided whether or not keeping the most voted answer shown on the screen or which the final answer was in the case of a tie. Each group had three lifelines of two categories: one "take a fifty:fifty" and two "call a friend." The TV show third lifeline, "poll the audience," is not considered because it is the basis of the contest in our version. Team working skills were worked in pairs or trios with the $2 \mathrm{Y}$ students to create heterogeneous subgroups in which peer discussion favors collaborative learning as well as better results in the contest. All subgroups were led by one top-ranked Kahoot student who selected their partner from the rest. All questions were different from those used previously in class for clicker training purposes and were answered by all groups/students irrespective of their evolution in the contest, that is, after failure, in order to maintain students' engagement throughout the session. Students were asked to justify their answer to know whether the option was selected by chance, possibility that cannot be ruled out in multiple-choice questions with a single correct answer. Discussion was completed by the instructor when needed. Students were finally graded (50\% of final contest score) based on the correct answers of each group or subgroup they belong to.

Since 3 Y games were played in two different days, two sets of questions (A and B) of similar difficulty were prepared for both Kahoot and Poll Everywhere. It is important to note that students' registration in the app implies access to all questions answered so first-day participants can communicate the questions to second-day participants.

After the review session, a unique and anonymous survey was sent to all 40 students taking advantage of this feature of Poll Everywhere. Finally, the students performed the exam and the learning outcomes were analyzed.

\section{Activity implementation}

Students were very receptive to this new activity at the time of presentation. During the training period, they actively participated in both forum and spontaneous instant polling in class. Nobody was reluctant to use their mobile phone to answer the questions and rapidly solved the initial problems such as connectivity and wrong answering by light clicking on the undesired bottom and become familiar with the apps.

The first minutes of the session class scheduled for the contest were dedicated to remember the rules and scoring, and then, the leaders were selected by Kahoot. It is interesting to note that though the distribution of correct answers was different in each trial as expected (Fig. 2a, b), the absence of 0 score as well as the lack of 5 score among the $2 \mathrm{Y}$ students points to influence of chance when answering. This is especially true in a quiz where quickness is essential.

The second phase was intended to be more reflexive so the limitation of time was removed. Results for Plickers-based second phase, summarized in Table 1, and for Poll Everywhere in Fig. 2c and Table 2, indicate that all pairs/trio (2Y) or individuals (3Y) provided correct responses for at least 8 out of 15 questions (more than 50\%) except in a single case (7 out of 15). Interestingly, only 2 questions out of 30 achieved $100 \%$ correct answers by $3 \mathrm{Y}$ students when analyzed individually while as a group they answered more than 12, showing the power of team working final decision. Similarly, 5 questions were correctly answered by $2 \mathrm{Y}$ groups. During the discussion following most failed questions, the majority of students recognized not having processed that content in theoretical classes. Therefore, the game offered valuable feedback not only to students but also to instructors to know where major difficulties are concentrated.

The results of the Poll Everywhere contest are of particular interest because of the large difference in performance between groups. Group (G) 1 and G2 failed game A at questions 5 and 6, respectively (Table 2), sooner than instructor's expectations achieving a poor score according to show rules, while group 3 failed game B at 13th and group 4 successfully completed the contest, in line with better results obtained in the selection phase (Fig. 2b). Since we did not stop the game after the first failure as in the TV show in order to revise as much topics as possible, we could compare the total number of failed questions as a group with the individual results shown in Fig. 2c. The final scores show that as a group, they only incorrectly answered less than 3 questions (Table 2), so all groups excelled in the test but the strict rules of the game penalized early failures at easier questions. Individually, the most abundant number of successful answers was 12 and 11 for G1 and G2, which contrasts with the early first wrong answer in the contest. This means that group result was higher than the individual ones as expected but the decision of some leaders was inadequate. As an example, the first G1 failure was the consequence of keeping the leader's own decision when the group mostly selected the right option (6:2). In the following failed question, this group leader decided to change his/her own decision that was correct, showing a lack of confidence due to the previous failure. Group leader 2 failed 5 questions individually, among the worst of this group. On the contrary G3 and G4 leaders actively promoted 


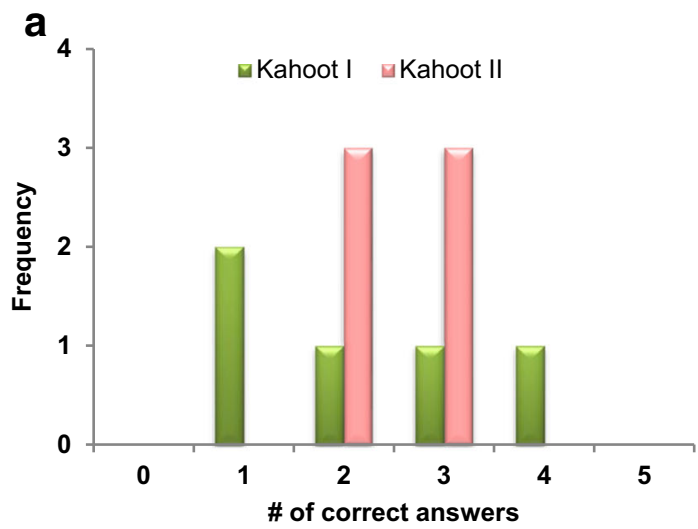

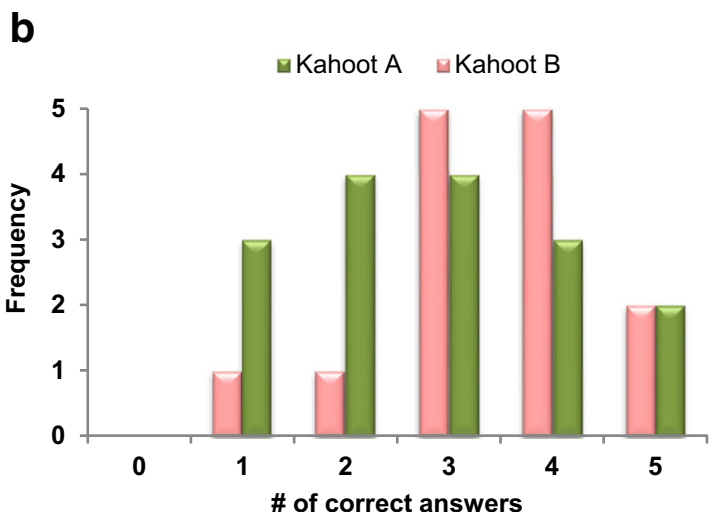

Fig. 2 Histograms showing the number of correct answers as a function of its frequency (number of students). a Kahoot selection phase played by $2 \mathrm{Y}$ students in two separate but consecutive sessions I (green dark color) and II (pink pale color) using the same game. b Kahoot selection phase

discussion after seeing the overall results on the screen to find arguments to decide and they used wisely some lifelines asking those colleagues they know are trustworthy. They intelligently pushed the group to higher scores than they would have obtained individually, including themselves; they asked successfully 11 and 13 questions, respectively.

\section{Evaluation of the project}

The evaluation of the project was performed through two main sources of information: students' opinion from a survey

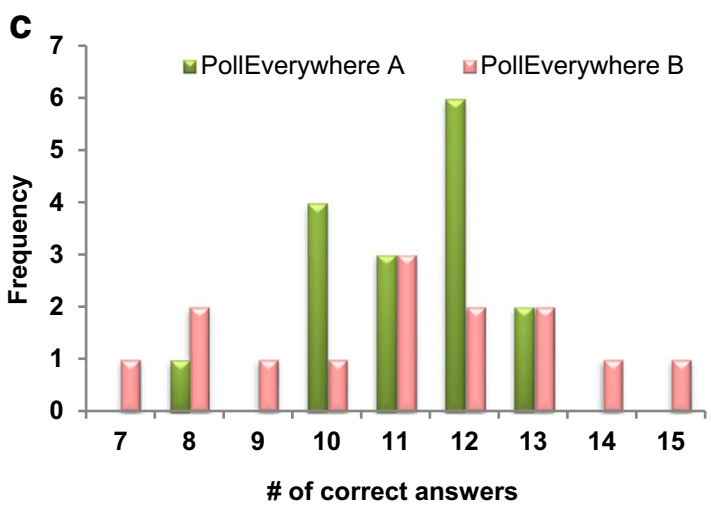

played by 3 Y students in two different days, games A (green dark color) and B (pink pale color), respectively. c TV show phase using Poll Everywhere played by $3 \mathrm{Y}$ students in two different days: game A (green dark color) and game B (pink pale color)

and learning outcomes from the final exam. The aim of the survey was to collect anonymous feedback about the most user-friendly app to be selected for future editions, how the activity promoted the study and change habits, the selfperceived outcomes if any, and suggestions to improve the activity. Fifty-five percent of students answered some survey questions and 50\% completed the poll. The overall satisfaction was high, above 7 (Fig. 3a). Poll Everywhere was the app with the best score in both classes but $2 \mathrm{Y}$ students emphasized Kahoot features such as easiness of use, attractive interface, and even the pressure time, while $3 \mathrm{Y}$ criticized this latter feature and the need of reading the answers in the room screen

Table 1 Results of the Plickers-based contest performed by second-year students (Analytical Chemistry I). C, correct answers shown in italic; $W$, wrong answers shown in bold

\begin{tabular}{|c|c|c|c|c|c|c|c|c|c|c|c|c|c|c|c|c|c|c|}
\hline & \multirow[t]{2}{*}{ Group } & \multirow[t]{2}{*}{ Correct answers } & \multirow[t]{2}{*}{ Failed questions } & \multicolumn{15}{|c|}{ Questions } \\
\hline & & & & 1 & 2 & 3 & 4 & 5 & 6 & 7 & 8 & 9 & 10 & 11 & 12 & 13 & 14 & 15 \\
\hline \multirow[t]{2}{*}{ Session I } & $\mathrm{A}$ & $8 / 15$ & $4-6,8,10,12,15$ & $C$ & $C$ & $C$ & $\mathbf{W}$ & W & W & $C$ & W & $C$ & W & $C$ & W & $C$ & $C$ & $\mathbf{W}$ \\
\hline & $\mathrm{B}$ & $10 / 15$ & $1,4,8,10,12$ & $\mathbf{W}$ & $C$ & $C$ & $\mathbf{W}$ & $C$ & $C$ & $C$ & $\mathbf{W}$ & $C$ & $\mathbf{W}$ & $C$ & $\mathbf{W}$ & $C$ & $C$ & $C$ \\
\hline \multirow[t]{3}{*}{ Session II } & $\mathrm{C}$ & $12 / 15$ & $1,8,10$ & $\mathbf{W}$ & $C$ & $C$ & $C$ & $C$ & $C$ & $C$ & $\mathbf{W}$ & $C$ & $\mathbf{W}$ & $C$ & $C$ & $C$ & $C$ & $C$ \\
\hline & $\mathrm{D}$ & $10 / 15$ & $1,8,12-14$ & W & $C$ & $C$ & $C$ & $C$ & $C$ & $C$ & $\mathbf{W}$ & $C$ & $C$ & $C$ & W & $\mathbf{W}$ & $\mathbf{W}$ & $C$ \\
\hline & $\mathrm{E}$ & $12 / 15$ & $1,10,15$ & W & $C$ & $C$ & $C$ & $C$ & $C$ & $C$ & W & $C$ & $\mathbf{W}$ & $C$ & $C$ & $C$ & $C$ & $\mathbf{W}$ \\
\hline
\end{tabular}


Table 2 Results of the Poll Everywhere contest performed by third-year students (Analytical Chemistry II)

\begin{tabular}{lllllll}
\hline & \multicolumn{2}{l}{ Game A } & & & Game B & \\
\cline { 2 - 3 } \cline { 5 - 6 } \cline { 5 - 6 } & Group 1 & Group 2 & & Group 3 & Group 4 \\
\hline Questions failed & $6,10,14$ & $5,11,14$ & 13 & None \\
Contest score & $6 / 15$ & $5 / 15$ & $13 / 15$ & $15 / 15$ \\
Group score & $12 / 15$ & $12 / 15$ & & $14 / 15$ & $15 / 15$ \\
Individual average score & $10.6 \pm 1.4$ & $11.8 \pm 1.1$ & & $10.5 \pm 2.0$ & $11.6 \pm 2.8$ \\
Average score per game & $11.2 \pm 1.4$ & & $11.0 \pm 2.4$ & \\
\hline
\end{tabular}

given that in the mobile app, only the answer logo/color appears. Implementation of clickers in primary and secondary schools has been progressive so the exposure to these tools might be higher for younger students. Most of $2 Y$ participants $(82 \%)$ reported previous experience with Kahoot in a learning context (namely at high school) which would explain the absence of anxiety. Plickers obtained the lowest average score.

Regarding the influence of the contest in the study habits and the expected results in the final exam, $76 \%$ of students recognized this activity has encouraged them to study because of the mandatory participation and grading without previous knowledge of the questions as in homework assignmentbased sessions. They are confident this will be reflected in the final mark not only for the early study but also because they can revise the questions before the examination. The rest declared no influence. Most students felt well (happy or very happy) when performing the activity with only 1 student reporting nervousness (Fig. 3b). Finally, all but one recommended implementation of this type of activity in the specific subject or even in all subjects (40\%). Students have proposed minute changes such as replacing the call lifeline by a 15 -s revision of the class notes, or allowing to change the response clicked, something that is possible with Poll Everywhere, the most accepted and versatile app.

Regarding the learning outcome, Fig. $3 \mathrm{c}$ shows the exam scoring for the previous academic year following a traditional review session in comparison with the present academic year. It is apparent that the curve is displaced to higher marks, suggesting the positive influence of the activity on the knowledge acquired.

\section{Concluding remarks}

The announcement of special activities as TV show contests has been generally welcomed and accepted even though they are real examination disguised of fun. These collaborative games are preferred by students to oral activities to check the level of understanding throughout the course because of the lower exposure to group and instructor scrutiny. Among the most favorable aspects of quiz contests, students pointed out the opportunity to confront their knowledge and debating topics with peers.
Fig. 3 Evaluation of the project. a Overall students' satisfaction in a $0-10$ scale. b Overall emotional scale when performing the game. c Learning outcomes in terms of final marks for the course with traditional review sessions (green squares) and with the contest (open blue circles)
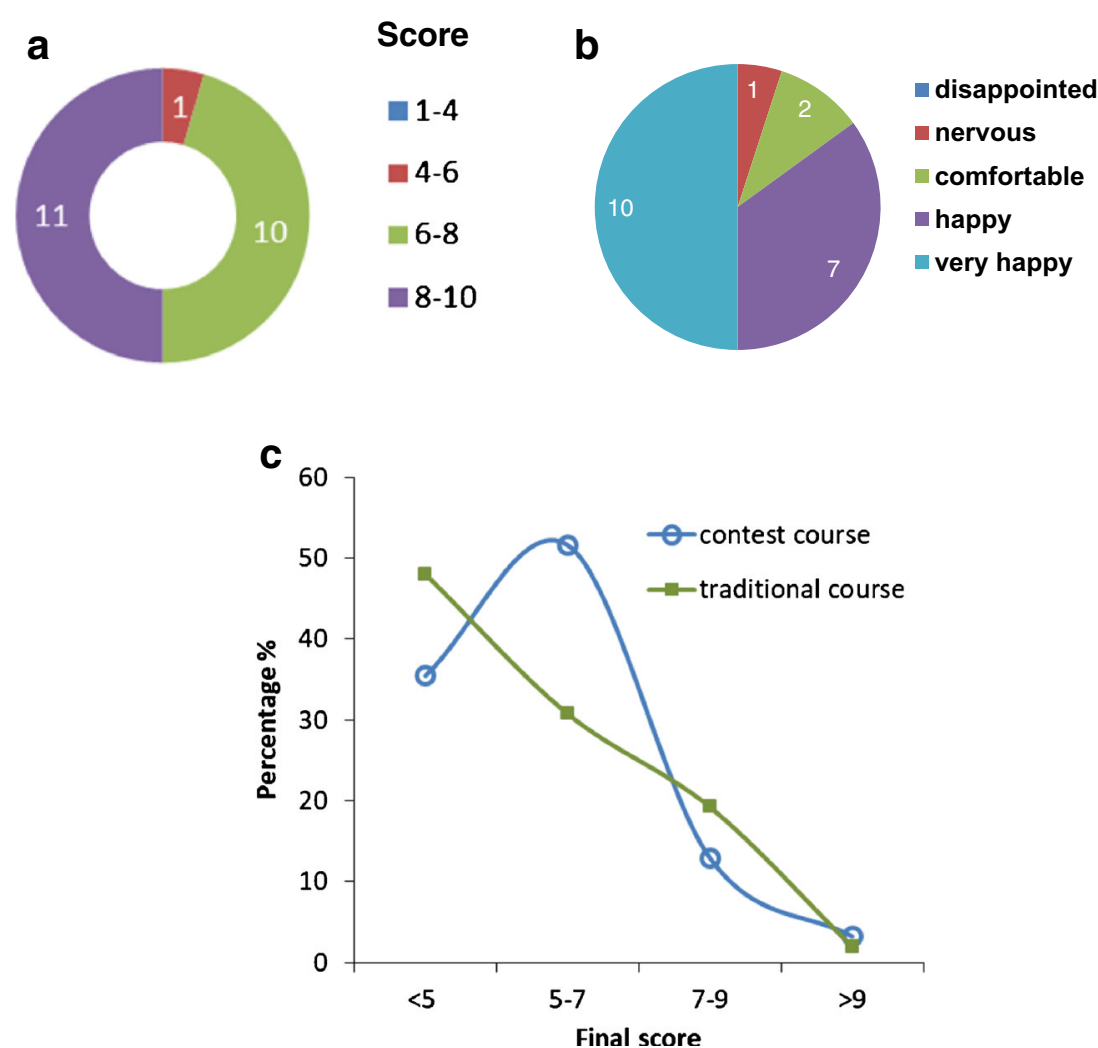
Students enjoy group learning processes but their approach to this task is mostly individual in spite of the variety of tools on hand that makes communication easier than ever before. The absence of predetermined questions/problems successfully promoted the study as the good score in the contest and especially the improved marks in the final examination demonstrated. We have also managed to keep students' attention and active participation during the whole review session. The feedback was very positive which encouraged us to repeat the experience in next academic years with some minor modifications that will improve the game outcome and performance but it will have no impact on the learning process.

Acknowledgments This pilot project is part of the innovation project PINN -19-A-026 to be implemented at the University of Oviedo.

\section{Compliance with ethical standards}

Conflict of interest The authors declare that they have no conflict of interest.

\section{References}

1. Stringfield TW, Kramer EF. Benefits of a game-based review module in chemistry courses for nonmajors. J Chem Educ. 2014;91(1): 56-8. https://doi.org/10.1021/ed300678f.

2. Capps K. Chemistry taboo: an active learning game for the general chemistry classroom. J Chem Educ. 2008;85(4):518-8. https://doi. org/10.1021/ed085p518.

3. Guardia JJ, Del Olmo JL, Roa I, Berlanga V. Innovation in the teaching-learning process: the case of Kahoot! On the horizon. 2019;27(1):35-45. https://doi.org/10.1108/oth-11-2018-0035.

4. Harrison CR. The use of digital technology in the class and laboratory. Anal Bioanal Chem. 2013;405(30):9609-14. https://doi.org/ 10.1007/s00216-013-7299-x.

5. Salzer R. Smartphones as audience response systems for lectures and seminars. Anal Bioanal Chem. 2018;410(6):1609-13. https:// doi.org/10.1007/s00216-017-0794-8.

6. Ferreiro-González M, Arnores-Arrocha A, Espada-Bellido E, Aliano-Gonzalez MJ, Vázquez-Espinosa M, González-de-Peredo $\mathrm{AV}$, et al. Escape classroom: can you solve a crime using the analytical process? J Chem Educ. 2019;96(2):267-73. https://doi.org/ 10.1021/acs.jchemed.8b00601.

7. Antunes M, Pacheco MAR, Giovanela M. Design and implementation of an educational game for teaching chemistry in higher education. $\mathrm{J}$ Chem Educ. 2012;89(4):517-21. https://doi.org/10.1021/ed2003077.

8. Henderson DE. A chemical instrumentation game for teaching critical thinking and information literacy in instrumental analysis courses. J Chem Educ. 2010;87(4):412-5. https://doi.org/10.1021/ed800110f.

9. Grinias JP. Making a game out of it: using web-based competitive quizzes for quantitative analysis content review. J Chem Educ. 2017;94(9):1363-6. https://doi.org/10.1021/acs.jchemed.7b00311.

10. Morrison RW, Caughran JA, Sauers AL. Classroom sesponse systems for implementing interactive inquiry in large organic chemistry classes. J Chem Educ. 2014;91(11):1838-44. https://doi.org/10. 1021/ed300688d.
11. Koh SBK, Fung FM. Applying a quiz-show style game to facilitate effective chemistry lexical communication. J Chem Educ. 2018;95(11):1996-9. https://doi.org/10.1021/acs.jchemed. $7 \mathrm{~b} 00857$.

12. Gibbons RE, Laga EE, Leon J, Villafane SM, Stains M, Murphy K, et al. Chasm crossed? Clicker use in postsecondary chemistry education. J Chem Educ. 2017;94(5):549-57. https://doi.org/10.1021/ acs.jchemed.6b00799.

13. Deavor JP. Who wants to be a (chemical) millionaire? J Chem Educ. 2001;78(4):467-7. https://doi.org/10.1021/ed078p467.

Publisher's note Springer Nature remains neutral with regard to jurisdictional claims in published maps and institutional affiliations.

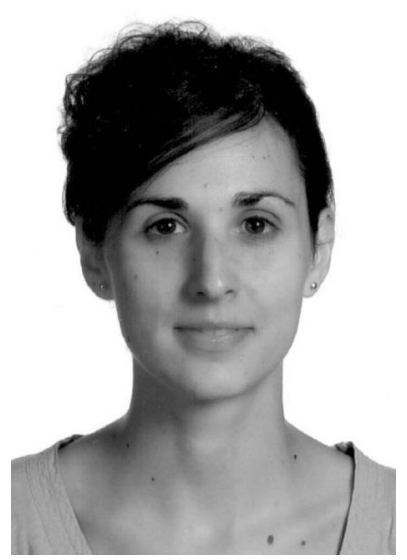

Rebeca Miranda-Castro is an Assistant Professor in the Department of Physical and Analytical Chemistry at the University of Oviedo (Spain). She has been teaching Analytical Chemistry in Chemistry, Biotechnology, and Industrial Chemical Engineering Degrees. She is an author of 4 book chapters of laboratory methods for undergraduate and master students. She participates in outreach activities to promote science among high school students (Science Week workshops) and she is involved in an innovation activity based on the use of mobile phones in Analytical Chemistry courses. Her current research interests focus on the development of electrochemical biosensing platforms for clinical diagnosis and food analysis using molecular recognition elements based on nucleic acids (genosensors and aptasensors).

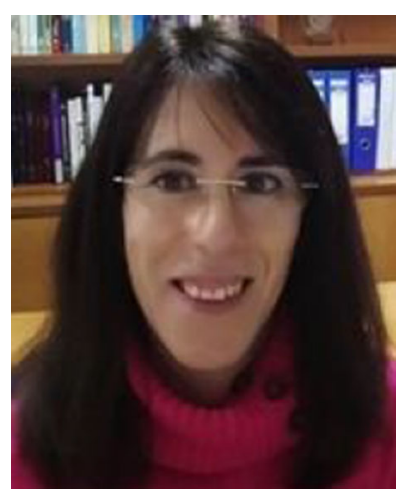

Noemí de-los-Santos-Álvarez is an Associate Professor of Analytical Chemistry at the University of Oviedo (Spain). Her current research interests include the selection and characterization of aptamers and the development of aptasensors and genosensors for tumor biomarker detection. She has taught Analytical Chemistry at undergraduate level in Chemistry, Chemical Engineering, and Biotechnology Degrees and also at graduate level in Chemistry where she is implementing several teaching innovation projects aimed at actively involving students in the classroom. 